\title{
вмј Global Health Is the single self-rated health item reliable in India? A construct validity study
}

\author{
Stéphane Cullati, ${ }^{1,2,3}$ Simantini Mukhopadhyay, ${ }^{4}$ Stefan Sieber, ${ }^{1,3}$
} Achin Chakraborty, ${ }^{4}$ Claudine Burton-Jeangros ${ }^{1,3}$

To cite: Cullati S,

Mukhopadhyay S, Sieber S, et al. Is the single selfrated health item reliable in India? A construct validity study. BMJ Glob Health 2018;3:e000856. doi:10.1136/ bmjgh-2018-000856

Handling editor Soumitra Bhuyan

- Additional material is published online only. To view please visit the journal online (http://dx.doi.org/10.1136/ bmjgh-2018-000856)

Received 28 March 2018 Revised 17 September 2018 Accepted 6 0ctober 2018

Check for updates

(c) Author(s) (or their employer(s)) 2018. Re-use permitted under CC BY-NC. No commercial re-use. See rights and permissions. Published by BMJ.

${ }^{1}$ Institute of Sociological Research, University of Geneva, Geneva, Switzerland

${ }^{2}$ Department of General Internal Medicine, Rehabilitation and Geriatrics, University of Geneva, Geneva, Switzerland ${ }^{3}$ Swiss NCCR 'LIVESOvercoming Vulnerability: Life Course Perspectives', University of Geneva, Geneva, Switzerland ${ }^{4}$ Institute of Development Studies, Kolkata, India

Correspondence to Stéphane Cullati; stephane.cullati@unige.ch

\section{ABSTRACT}

Introduction In high-income countries, the self-rated health (SRH) item is used in health surveys to capture the population's general health because of its simplicity and satisfactory validity and reliability. Despite scepticism about its use in low-income and middle-income countries, India implemented the SRH item in many of its demographic and population health surveys, but evidence of its validity is lacking. The objective was to assess the construct validity of the SRH item in India.

Methods Data for 4492 men and 4736 women from the Indian sample of the World Health Survey (2003) were used. Overall, 43 health status indicators were grouped into health dimensions (physical, mental and functional health, chronic diseases, health behaviours) and the SRH item was regressed on these indicators by using sexstratified multivariable linear regressions, adjusted with demographic and socioeconomic variables.

Results Respondents (participation rate 95.6\%; mean age 38.9 years) rated their health as very good (21.8\%), good $(36.4 \%)$, moderate $(26.6 \%)$, bad $(13.2 \%)$ or very bad (2.0\%). Among men, the adjusted explained SRH variance by health dimensions ranged between $18 \%$ and $41 \%$ (physical $33 \%$, mental $32 \%$, functional health $41 \%$, chronic diseases $23 \%$, health behaviours $18 \%$ ). In multivariable models, the overall explained variance increased to $45 \%$. The 43 health status indicators were associated with SRH and their effect sizes were in the expected direction. Among women, results were similar (overall explained variance $48 \%$ ).

Conclusion The SRH item has satisfactory construct validity and may be used to monitor health status in demographic and population health surveys of India.

\section{INTRODUCTION}

In high-income countries, the self-rated health (SRH) item is widely used in demographic and population health surveys to capture respondents' self-reported general health. This item is often worded as "Would you say your health is... excellent/very good/ good/fair/poor", although various phrasing and response scales have been used. ${ }^{1-4}$ Reasons explaining the success of this health item are its simplicity (one question), validity

\section{Key questions}

What is already known?

- The self-rated health (SRH) item is commonly used in health surveys to capture a population's general health; however, its use in low-income and middle-income countries has been met with scepticism.

- India is using the SRH item in demographic and population health surveys, but evidence of its validity is lacking.

What are the new findings?

- The SRH item has satisfactory construct validity in the context of India.

What do the new findings imply?

- Institutions conducting large-scale health surveys in India may use the SRH item to monitor health status of the general adult population.

and reliability. ${ }^{135-9}$ In high-income countries, the SRH item predicts mortality, ${ }^{10-16}$ uses of health services, and health expenditures in large and representative surveys of the adult general population. ${ }^{14-17-19}$ However, the SRH item has been found sensitive to the respondent's culture in response styles. ${ }^{20-22}$

In low-income and middle-income countries, the use of self-reported measures of health statuses, like the SRH item and other health status measures (diabetes, cancer, etc), is viewed with scepticism. Self-reported measures of health status among disadvantaged groups may be misleading because health self-assessment may be influenced by the social conditions of respondents and by lack of medical facilities. Thus, respondents may fail to perceive illness or health deficits because of lack of awareness. ${ }^{23}$ Although this view has been supported by studies using health vignettes,${ }^{20}{ }^{24-27}$ validation studies of the SRH item in low-income and middle-income countries remain rare. ${ }^{28-35}$

Nevertheless, the SRH item has been implemented in many demographic and 
population health surveys of low-income and middle-income countries, such as India. ${ }^{36-38}$ In this country, methodological research examining the validity of the SRH item is scarce. Five studies supported emerging evidence of its acceptable validity: one observed that the social gradient between socioeconomic position and the SRH item followed the expected direction, which supported its face validity. ${ }^{39}$ One study of older respondents examined the SRH item's criterion validity, ${ }^{40}$ two its predictive validity with mortality, and another differences in cut-off points across the SRH item's response options. ${ }^{41-43}$ To our knowledge, no study has examined the construct validity of the SRH item in the general adult population of India.

With the second largest population in the world, representing $17.5 \%$ of the world's population, ${ }^{44}$ India is facing the double burden of communicable and non-communicable diseases. ${ }^{45}$ Therefore, monitoring its population health is critical. The SRH item may contribute to this monitoring, but evidence of its validity is lacking. The objective of this construct validity study was to determine whether the SRH item is a reliable indicator of general self-reported health in India.

\section{METHODS \\ Study design}

This study is part of a project whose primary aim is the comparative study of health inequalities in India and Switzerland. This study used the Indian sample of the World Health Survey (WHS). The WHS is a data collection platform to obtain comparable information on population health and health systems of WHO member states. ${ }^{46}$ We used data from the 2003 cross-sectional survey that surveyed adults aged 18 years and older from the general population living in six Indian states. ${ }^{47}$ Households were selected following a stratified random sampling. One member of each selected household was then randomly selected. Participation rate was $95.6 \%{ }^{47}$

\section{Variables}

The survey questionnaire is available from WHO's WHS website. ${ }^{48}$ The SRH item asked "In general, how would you rate your health today?" and answer modalities were very bad (1), bad, moderate, good and very good (5). Satisfaction with health asked with "How satisfied are you with your health?" and answer modalities ranged from 1 (very dissatisfied) to 5 (very satisfied). Satisfaction with health was used to report its correlation with the SRH item (convergent validity). The questionnaire included several health status variables. Because the SRH item captures a range of health dimensions, ${ }^{49}$ we grouped these health status variables into dimensions on the basis of the literature: physical health, chronic diseases, infectious diseases, mental health, functional health ${ }^{50-62}$ and health behaviours. ${ }^{49} 586163$ Physical health variables included Body Mass Index (BMI), bodily aches or pains, bodily discomfort, feeling of tightness in the chest, pain in the chest when walking, back pain, pain/aching/stiffness or swelling in or around the joint (eg, arms, hands, legs or feet), stiffness in the joint lasting more than 30 min, attacks of wheezing or whistling breathing, attacks of shortness of breath that came on without obvious cause, problems with mouth and/or teeth, and angina or angina pectoris. Chronic disease variables included having been diagnosed (yes, no) with arthritis, asthma and diabetes. Infectious disease variables included a single question asking if respondents had a tuberculosis test in the last 12 months (yes, no). Mental health variables included depression diagnosis, feeling sad/low or depressed, loss of interest, feeling tired/exhausted or without energy, problems with sleeping, problems with concentrating, problems with learning a new task, feeling rested and refreshed, feeling worried or anxious, schizophrenia diagnosis, being unable to control the important things in life and not being able to cope with all the things that had to be done. Functional health variables included limitations in daily activities, moving around, physical activities (running $3 \mathrm{~km}$ (or equivalent) or cycling), selfcare, taking care of general appearance, personal relationships or participation in the community, dealing with conflicts and tensions, recognising a person across the road and reading. Answer modalities for physical, mental and functional health variables were 1 (none), 2 (mild), 3 (moderate), 4 (severe) and 5 (extreme/ cannot do) and were re-coded as presence $(1=$ mild or moderate or severe or extreme) or absence $(0=$ none) BMI was defined according to the Quetelet definition $\left(\mathrm{kg} / \mathrm{m}^{2}\right)$, but most respondents used a foot scale to report their height, rounded to the unit $(1,2,3$, etc) Answers for BMI were grouped into underweight $(<18.5$ $\left.\mathrm{kg} / \mathrm{m}^{2}\right)$, normal weight $\left(18.5\right.$ to $\left.<25.0 \mathrm{~kg} / \mathrm{m}^{2}\right)$, overweight $\left(25.0\right.$ to $\left.<30.0 \mathrm{~kg} / \mathrm{m}^{2}\right)$ and obesity $\left(\geq 30.0 \mathrm{~kg} / \mathrm{m}^{2}\right)$. Health behaviour variables included currently smoking (yes, no), drinking alcohol in the last 7 days (yes, no), vigorous or moderate physical activity in the last 7 days (yes, no), eating fruits daily and eating vegetables daily. Drinking alcohol assessed how many standard drinks of any alcoholic beverage respondents drank on each of the past 7 days. Respondents were classified by whether they drank alcohol in the past week or not. Questions on physical activities assessed whether respondents engaged in vigorous physical activities (making them "breathe much harder than normal and may include heavy lifting, digging, aerobics, or fast bicycling") or moderate physical activities (making them "breathe somewhat harder than normal and may include carrying light loads, bicycling at a regular pace, or doubles tennis"). In total, 45 health status variables were used in the analysis. Missing data on these variables were estimated by multiple imputations (creating 20 imputed datasets) ${ }^{64}$ Missing data were not imputed for chronic diseases variables, which where built on information from three questions ("Have you ever been diagnosed with...", "Have you ever been treated for...", "Have you been taking (drug medications related to the chronic disease) in the last 2 weeks?"). 
Respondents answered questions about their sex, age (continuous; re-coded as 18-35, 36-59 and $\geq 60$ years old), education (no, primary, secondary, post-secondary), household permanent income, employment (not in vs in the labour force), marital status (single, married, separated, divorced, widowed), religion (Hindu, Christian, Muslim, other, no affiliation), residence area (urban vs rural) and states of residence (Assam, Karnataka, Maharastra, Rajasthan, Uttar Pradesh, West Bengal). No education included no formal schooling or less than primary school. Education levels corresponded to the International Standard Classification of Education levels. ${ }^{65}$ Household permanent income was based on the possession of 16 assets in the household: whether the household had electricity (yes, no), a bicycle, a clock, a bucket, a washing machine for clothes, a dishwasher, a refrigerator, a fixed telephone line, a mobile or cellular telephone, a television, a computer, a moped or scooter or motorcycle, livestock (cattle only), a sewing machine, a radio or transistor or tape recorder and a bullock cart. Respondents were classified across the quintile distribution of the household permanent income. ${ }^{47}$ A question on employment asked about respondents' current job. Respondents in the labour force included government employees, non-government employees, self-employed workers and employers. Respondents not in the labour force included all other respondents.

\section{Statistical analyses}

Self-rated health was the dependent variable. Multivariable linear regression models were used to assess the contribution of each health status variable. First, we estimated bivariable associations between the 43 health status variables and the SRH item (one health status variable, one model; BMI was a four-category variable, with normal weight as reference). These 43 models were adjusted for the SRH item's covariates from the Indian literature, that is, age, education, household income, employment, marital status, religion, rural residence and Indian state. ${ }^{6-75}$ Second, we estimated multivariable models including the 43 health status variables in the same model, adjusting for the SRH item's covariates. In bivariable and multivariable models, we assessed two characteristics of the effect size: its statistical significance and whether its direction (positive or negative sign of the estimate) was expected or not. Explained variances for health status variables and health dimensions were computed with the $\mathrm{R}^{2}$ coefficient. All analyses involved using SPSS V.25 and were conducted separately for women and men because sex differences in rating health status is well known across countries ${ }^{7677}$ and in India. ${ }^{69}$

\section{Robustness analyses}

First, the models were replicated with a recoded binary SRH variable ${ }^{78}$ : good (very good, good, moderate) versus poor (poor, very poor). Second, to assess the performance of the SRH item in India, we conducted a cross-cultural construct validation comparison with
Switzerland, a top high-income country, showing large differences from India in terms of health and economic indicators (online supplementary material 1 ). We used the data from the Swiss Health Interview Study (SHIS), a nationally representative repeated cross-sectional survey, and ran the same statistical analyses (described above) by using 19 health status variables that were common to the WHS and SHIS. Because the SRH item changed over the SHIS waves (both the question's formulation and the answer modalities), we selected the wave 2007 , when the SRH item's formulation was identical to that of the WHS. The Swiss sample consisted of 7702 men and 8949 women. The cross-cultural construct validation analysis followed two steps: first, we estimated bivariable associations between the 19 health status variables and the SRH item among men and women in each country and reported the explained variance $\left(R^{2}\right)$ for the health status variables and health dimensions; second, we estimated multivariable models by using the same stepwise procedure of the main analysis. Bivariable and multivariable analysis adjusted for the following covariates of the SRH item: age, education, household income, employment, marital status, religion and rural residence; the Indian sample was adjusted by Indian state too. In India, household income was a score of household assets whereas in Switzerland this variable represented the monthly net household income weighted by number of household members and number of children $\leq 14$ years old. Though not being similar, both household income variables captured respondent's socioeconomic position in their respective countries and were used as control in the multivariable models.

\section{Sensitivity analyses}

First, we ran the same analyses on the whole sample without sex stratification. Second, we replicated the models by stratifying with age as $18-35,36-59$ and $\geq 60$ years. This stratification was justified by the fact that health status ratings are age-dependent and older individuals tend to exhibit optimism. ${ }^{55}$ 79-83 Third, we replicated the models by stratifying on education, taking into account evidence suggesting that reliability of the SRH item may be lower among disadvantaged than advantaged people and that the meaning of ratings varies by education. ${ }^{55818485}$

\section{RESULTS}

\section{Participant characteristics}

SRH responses and other health status characteristics for participants are reported in table 1 for men and women (see online supplementary material 1 for demographic and socioeconomic characteristics).

\section{Construct validity}

Bivariable associations between the 43 health status variables and the SRH item are reported in table 2. Among men, all health status variables were associated with the SRH item, except for drinking alcohol and eating 
Table 1 Health status of respondents in India, World Health Survey, 2003

\begin{tabular}{|c|c|c|}
\hline & Men & Women \\
\hline & $\mathbf{N}(\%)$ & $\mathbf{N}(\%)$ \\
\hline Self-rated health, by response options: & & \\
\hline Bad & $463(10.3)$ & $755(15.9)$ \\
\hline Moderate & $1167(26.0)$ & $1285(27.1)$ \\
\hline Very good & $1129(25.1)$ & $887(18.7)$ \\
\hline Self-rated health, continuous, 1 (very bad) to 5 (very good) (mean, SD) & $3.73(1.01)$ & $3.53(1.04)$ \\
\hline Physical health & & \\
\hline BMI & & \\
\hline Underweight & $500(11.1)$ & $1001(21.1)$ \\
\hline Obesity & $375(8.3)$ & $594(12.5)$ \\
\hline Bodily aches or pains & $2300(51.4)$ & $3034(64.1)$ \\
\hline Bodily discomfort & $2045(45.8)$ & $2818(59.5)$ \\
\hline Tightness in chest & $501(11.1)$ & $523(11.0)$ \\
\hline Pain in chest when walking & $525(11.9)$ & $831(17.6)$ \\
\hline Back pain & $1301(29.0)$ & $2045(43.2)$ \\
\hline Pain, aching, stiffness or swelling in or around the joint (like arms, hands, legs or feet) & $927(20.6)$ & $1427(30.1)$ \\
\hline Stiffness in the joint lasting more than 30 min & $313(6.9)$ & $464(10.0)$ \\
\hline Attacks of wheezing or whistling breathing & $521(11.4)$ & $448(9.5)$ \\
\hline Diabetes & $172(3.8)$ & $103(2.2)$ \\
\hline Infectious diseases & & \\
\hline Tuberculosis & $157(3.2)$ & $96(2.0)$ \\
\hline Mental health & & \\
\hline Depression diagnosis & $556(12.4)$ & $660(13.9)$ \\
\hline Feeling sad, low or depressed & $1481(33.0)$ & $1827(38.5)$ \\
\hline Loss of interest & $1219(27.1)$ & 1494 (31.6) \\
\hline Feeling tired, exhausted or without energy & $1376(30.6)$ & $1661(35.1)$ \\
\hline Problems with sleeping & $1351(30.1)$ & $1864(39.4)$ \\
\hline Problems with concentrating & 1709 (38.3) & $2369(50.0)$ \\
\hline Problems with learning a new task & $1615(36.1)$ & $2191(46.3)$ \\
\hline Feeling rested and refreshed & $1542(34.4)$ & $2044(43.2)$ \\
\hline Feeling worried or anxious & $2020(45.0)$ & $2462(52.0)$ \\
\hline Schizophrenia diagnosis & $124(2.8)$ & $164(3.4)$ \\
\hline Unable to control the important things in his/her life & $575(12.7)$ & $728(15.4)$ \\
\hline Not cope with all the things that he/she had to do & $830(18.5)$ & $928(19.6)$ \\
\hline
\end{tabular}

Functional health 


\begin{tabular}{|c|c|c|}
\hline & Men & Women \\
\hline & $\mathbf{N}(\%)$ & $\mathbf{N}(\%)$ \\
\hline Limitations in daily activities & $1972(43.9)$ & $2592(54.7)$ \\
\hline Limitations in moving around & $1743(38.8)$ & $2392(50.5)$ \\
\hline Limitations in vigorous activities & $2057(45.8)$ & $2847(60.1)$ \\
\hline Limitations in self-care & $1029(22.9)$ & $1583(33.4)$ \\
\hline Limitations in taking care of general appearance & $920(20.5)$ & $1360(28.7)$ \\
\hline Limitations in personal relationships or participation in the community & $1091(24.3)$ & $1550(32.7)$ \\
\hline Limitations in dealing with conflicts and tensions & $1200(26.7)$ & $1735(36.7)$ \\
\hline Limitations in recognising a person across the road & $1043(23.8)$ & $1400(29.6)$ \\
\hline Limitations in reading & $1017(22.6)$ & $1236(26.1)$ \\
\hline \multicolumn{3}{|l|}{ Health behaviours } \\
\hline Smoking (yes) & $2359(52.5)$ & $764(16.1)$ \\
\hline Drinking alcohol last 7 days & $488(10.9)$ & $52(1.1)$ \\
\hline Vigorous and moderate physical activity last 7 days & $3872(86.2)$ & $4001(84.5)$ \\
\hline Eating fruits daily & $3167(70.5)$ & $3260(68.9)$ \\
\hline Eating vegetables daily & 4469 (99.4) & $4702(99.3)$ \\
\hline
\end{tabular}

BMI, Body Mass Index.

vegetables. Explained variance across health dimensions ranged from 0.179 (health behaviours) to 0.412 (functional health). Among women, all health status variables were associated with the SRH item, with the exception of overweight and obesity status, drinking alcohol, physical activity and eating vegetables. Explained variance across health dimensions ranged from 0.176 (health behaviours) to 0.444 (functional health).

The directions of the effect sizes were as expected across all health status variables (ie, poor health status was associated with low SRH), with a few exceptions: among men, being overweight, obese and drinking alcohol were associated with good $\mathrm{SRH}$, and eating vegetables was associated with poor SRH; among women, unexpected coefficients were for obesity, drinking alcohol and physical activity, but associations were not significant.

Multivariable analyses are reported in table 3. Among men, 18 health status variables remained associated with the SRH item. The directions of the effect sizes were as expected (ie, poor health status was associated with low $\mathrm{SRH}$ ), except for being overweight, obese, having problems with concentrating and drinking alcohol. The model explained 0.453 of the variance and included all health dimensions, except for infectious disease: physical health (five variables), chronic diseases (one variable), mental health (six variables), functional health (three variables) and health behaviours (three variables). Among women, 19 health status variables remained associated with the SRH item and coefficient signs were as expected (ie, poor health status was associated with low SRH), except pain in or around the joint. The model explained 0.483 of the variance and included all health dimensions: physical health (six variables), chronic diseases (one variable), infectious diseases (one variable), mental health (four variables), functional health (six variables) and health behaviours (one variable). Eighteen variables were not associated with the SRH item among men and women: being underweight, bodily aches or pains, tightness in chest, attacks of wheezing or whistling breathing, attack of shortness of breath, angina, arthritis, diabetes, depression diagnosis, feeling sad or empty or depressed, loss of interest, feeling rested and refreshed, schizophrenia diagnosis, limitations in taking care of appearance, limitations in dealing with conflicts and tensions, and limitations in recognising a person across the road, physical activity and eating vegetables daily.

\section{Convergent validity}

The correlation between the SRH item and the satisfaction with health item was $0.506(\mathrm{p}<0.001)$.

\section{Robustness analyses}

First, results did not change when the SRH item was re-coded as a binary variable (data not shown), with a few exceptions among health behaviour variables (on univariable and multivariable analyses): among men, being obese and drinking alcohol were no longer associated, whereas among women, physical activity was now positively associated and eating fruits no longer associated. On multivariable analyses, the number of health status variables significantly associated with the binary SRH was lower than with the linear SRH. Health status variables associated with the binary SRH covered the same health dimensions as with the linear SRH (except for the chronic diseases dimension among women, no variables associated). In general, directions of effect sizes 
Table 2 Health status and self-rated health *: bivariable cross-sectional associations †, World Health Survey, 2003

\begin{tabular}{|c|c|c|c|c|c|c|}
\hline & \multicolumn{3}{|c|}{ Men $\mathrm{n}=4492$} & \multicolumn{3}{|c|}{ Women $n=4736$} \\
\hline & B & $P$ values & $\begin{array}{l}\text { Adjusted } \\
\mathbf{R}^{2}\end{array}$ & B & $P$ values & $\begin{array}{l}\text { Adjusted } \\
\mathbf{R}^{2}\end{array}$ \\
\hline Physical health & & & 0.328 & & & 0.344 \\
\hline BMI (reference normal weight) & & & 0.180 & & & 0.168 \\
\hline Underweight & -0.175 & $<0.001$ & & -0.118 & 0.001 & \\
\hline Overweight & 0.202 & $<0.001$ & & -0.032 & 0.430 & \\
\hline Obesity & 0.199 & $<0.001$ & & 0.004 & 0.931 & \\
\hline Bodily aches or pains & -0.679 & $<0.001$ & 0.270 & -0.776 & $<0.001$ & 0.284 \\
\hline Bodily discomfort & -0.724 & $<0.001$ & 0.282 & -0.800 & $<0.001$ & 0.297 \\
\hline Tightness in chest & -0.598 & $<0.001$ & 0.201 & -0.471 & $<0.001$ & 0.186 \\
\hline Pain in chest when walking & -0.498 & $<0.001$ & 0.193 & -0.515 & $<0.001$ & 0.201 \\
\hline Back pain & -0.504 & $<0.001$ & 0.215 & -0.510 & $<0.001$ & 0.222 \\
\hline Pain, aching, stiffness in the joint & -0.417 & $<0.001$ & 0.194 & -0.428 & $<0.001$ & 0.200 \\
\hline Stiffness in the joint & -0.585 & $<0.001$ & 0.189 & -0.557 & $<0.001$ & 0.190 \\
\hline Attacks of wheezing or whistling breathing & -0.496 & $<0.001$ & 0.191 & -0.388 & $<0.001$ & 0.178 \\
\hline Attacks of shortness of breath & -0.591 & $<0.001$ & 0.190 & -0.604 & $<0.001$ & 0.189 \\
\hline Problems with mouth and/or teeth & -0.292 & $<0.001$ & 0.179 & -0.331 & $<0.001$ & 0.187 \\
\hline Angina or angina pectoris & -0.498 & $<0.001$ & 0.189 & -0.454 & $<0.001$ & 0.184 \\
\hline Chronic diseases & & & 0.227 & & & 0.208 \\
\hline Arthritis & -0.459 & $<0.001$ & 0.196 & -0.402 & $<0.001$ & 0.193 \\
\hline Asthma & -0.742 & $<0.001$ & 0.201 & -0.530 & $<0.001$ & 0.181 \\
\hline Diabetes & -0.414 & $<0.001$ & 0.174 & -0.500 & $<0.001$ & 0.171 \\
\hline \multicolumn{7}{|l|}{ Infectious diseases } \\
\hline Tuberculosis & -0.606 & $<0.001$ & 0.179 & -0.600 & $<0.001$ & 0.172 \\
\hline Mental health & & & 0.324 & & & 0.347 \\
\hline Depression diagnosis & -0.453 & $<0.001$ & 0.189 & -0.394 & $<0.001$ & 0.183 \\
\hline Feeling sad, empty or depressed & -0.424 & $<0.001$ & 0.206 & -0.539 & $<0.001$ & 0.229 \\
\hline Loss of interest & -0.457 & $<0.001$ & 0.207 & -0.534 & $<0.001$ & 0.222 \\
\hline Feeling tired, exhausted or without energy & -0.471 & $<0.001$ & 0.212 & -0.549 & $<0.001$ & 0.227 \\
\hline Problems with sleeping & -0.664 & $<0.001$ & 0.252 & -0.638 & $<0.001$ & 0.245 \\
\hline Problems with concentrating & -0.538 & $<0.001$ & 0.230 & -0.637 & $<0.001$ & 0.252 \\
\hline Problems with learning a new task & -0.545 & $<0.001$ & 0.229 & -0.510 & $<0.001$ & 0.220 \\
\hline Feeling rested and refreshed & -0.650 & $<0.001$ & 0.255 & -0.652 & $<0.001$ & 0.252 \\
\hline Feeling worried or anxious & -0.585 & $<0.001$ & 0.245 & -0.666 & $<0.001$ & 0.260 \\
\hline Schizophrenia diagnosis & -0.467 & $<0.001$ & 0.174 & -0.378 & $<0.001$ & 0.171 \\
\hline Unable to control important things in life & -0.399 & $<0.001$ & 0.185 & -0.482 & $<0.001$ & 0.193 \\
\hline Not cope with all things & -0.403 & $<0.001$ & 0.191 & -0.482 & $<0.001$ & 0.199 \\
\hline Functional health & & & 0.412 & & & 0.444 \\
\hline Limitations in daily activities & -0.982 & $<0.001$ & 0.374 & -1.051 & $<0.001$ & 0.394 \\
\hline Limitations in moving around & -0.765 & $<0.001$ & 0.288 & -0.840 & $<0.001$ & 0.312 \\
\hline Limitations in vigorous activities & -0.744 & $<0.001$ & 0.282 & -0.799 & $<0.001$ & 0.290 \\
\hline Limitations in self-care & -0.753 & $<0.001$ & 0.255 & -0.739 & $<0.001$ & 0.267 \\
\hline Limitations in taking care of appearance & -0.744 & $<0.001$ & 0.248 & -0.703 & $<0.001$ & 0.252 \\
\hline $\begin{array}{l}\text { Limitations in personal relationships or participation } \\
\text { in the community }\end{array}$ & -0.573 & $<0.001$ & 0.223 & -0.574 & $<0.001$ & 0.228 \\
\hline
\end{tabular}




\begin{tabular}{|c|c|c|c|c|c|c|}
\hline & \multicolumn{3}{|c|}{ Men $\mathrm{n}=4492$} & \multicolumn{3}{|c|}{ Women $\mathrm{n}=4736$} \\
\hline & B & $P$ values & $\begin{array}{l}\text { Adjusted } \\
\mathbf{R}^{2}\end{array}$ & B & $P$ values & $\begin{array}{l}\text { Adjusted } \\
\mathbf{R}^{2}\end{array}$ \\
\hline Limitations in dealing with conflicts and tensions & -0.508 & $<0.001$ & 0.213 & -0.471 & $<0.001$ & 0.209 \\
\hline Limitations in recognising a person across the road & -0.358 & $<0.001$ & 0.188 & -0.463 & $<0.001$ & 0.198 \\
\hline Limitations in reading & -0.324 & $<0.001$ & 0.183 & -0.452 & $<0.001$ & 0.197 \\
\hline Health behaviours & & & 0.179 & & & 0.176 \\
\hline Smoking & -0.121 & $<0.001$ & 0.171 & -0.232 & $<0.001$ & 0.172 \\
\hline Drinking alcohol last 7 days & 0.041 & 0.346 & 0.168 & 0.097 & 0.463 & 0.166 \\
\hline Vigorous or moderate physical activity last 7 days & 0.159 & $<0.001$ & 0.170 & -0.011 & 0.780 & 0.166 \\
\hline Eating fruits daily & 0.191 & $<0.001$ & 0.174 & 0.125 & $<0.001$ & 0.170 \\
\hline Eating vegetables daily & -0.007 & 0.973 & 0.168 & 0.111 & 0.536 & 0.166 \\
\hline
\end{tabular}

*Very bad $=1$, very good $=5$.

†Adjusted for age, education, household income, employment, marital status, religion, residence and Indian states. BMI, Body Mass Index.

were similar and explained variances were lower with the binary than linear SRH.

Second, construct validity was compared between India and Switzerland. Distribution of the health status variables in the WHS and SHIS are reported elsewhere (online supplementary table s3). Overall, health was poorer in the Indian than Swiss sample. On bivariable analyses, variance of the SRH item explained by the 19 health status variables is reported in online supplementary table S4. Explained variance across the 19 health status variables and across the five health dimensions was systematically higher in the Indian than Swiss sample among men, with differences in explained variances ranging from 5.0\% to $15.0 \%$; among women, results were similar (range of differences $6.9 \%$ to $19.0 \%$ ). Multivariable analyses are reported in online supplementary table S5 (men) and table S6 (women). Among men, the explained variance was higher in India than Switzerland (0.430 vs 0.291); among women, results were similar (0.448 and 0.300 , respectively). In both countries, among men and women, the SRH item was associated with health status variables covering physical health, chronic diseases, mental health, functional health, and health behaviours.

\section{Sensitivity analyses}

In the overall sample (men and women together), results were similar to the main analysis (data not shown): directions of effect sizes were expected and factors included the five health dimensions. Overweight, obesity, pain in the joint, drinking alcohol and eating fruits were positively associated with the SRH item. Bodily aches or pains was now associated with the SRH item.

The SRH item performed well across age groups. On univariable analyses, the 43 health status variables were significantly associated with the SRH item across the three age groups (except schizophrenia among people $\geq 60$ years old) and all effect sizes were consistent and similar to the main analysis (data not shown). Explained variances of health dimensions were reasonable (online supplementary table S7—column 'Explained variance'). In the multivariable models, most effect sizes were as expected in the 18-35, 36-59 and $\geq 60$ age groups (online supplementary table S8-column 'Proportions of expected effect sizes'). Models explained 0.398, 0.455 and 0.436 of the variance, respectively.

The SRH item has satisfactory construct validity across all educational groups, except respondents with post-secondary education (online supplementary table S8-column 'Explained variance'). In the multivariable models, most effect sizes were as expected in the no education, primary and secondary educational groups (online supplementary table S8-column 'Proportions of expected effect sizes') but not in the post-secondary group. Models explained 0.489, 0.464, 0.362 and 0.155 of the variance, respectively.

\section{DISCUSSION}

The objective of this construct validity study was to determine whether the SRH item translates into dimensions of health, in other words, to clarify what this item actually measures. The main finding of this study supports the SRH item as having satisfactory construct validity in the Indian context. Four arguments support this result.

First, as expected ${ }^{49}$ the SRH item captured the main dimensions of general health (ie, physical, mental and functional health; chronic diseases and health behaviours). ${ }^{49-63}$ Explained variances of these dimensions were satisfactory among both men (range 0.179$0.412)$ and women (0.176-0.444), and the direction of the effect sizes was as expected. This 'multidimensionality' of SRH was robust considering that (1) these dimensions were observed in univariate and multivariate analyses; (2) all analyses were adjusted with sociodemographic, socioeconomic and marital life factors known to be associated with SRH in India ${ }^{66-74}$; and (3) we used 
Table 3 Health status and self-rated health *: multivariable cross-sectional associations 2, World Health Survey, 2003

\begin{tabular}{llll} 
Men $n=4492$ & & \multicolumn{2}{l}{ Women $n=4736$} \\
& P values & B & $P$ values
\end{tabular}

Physical health

BMI (reference normal weight)

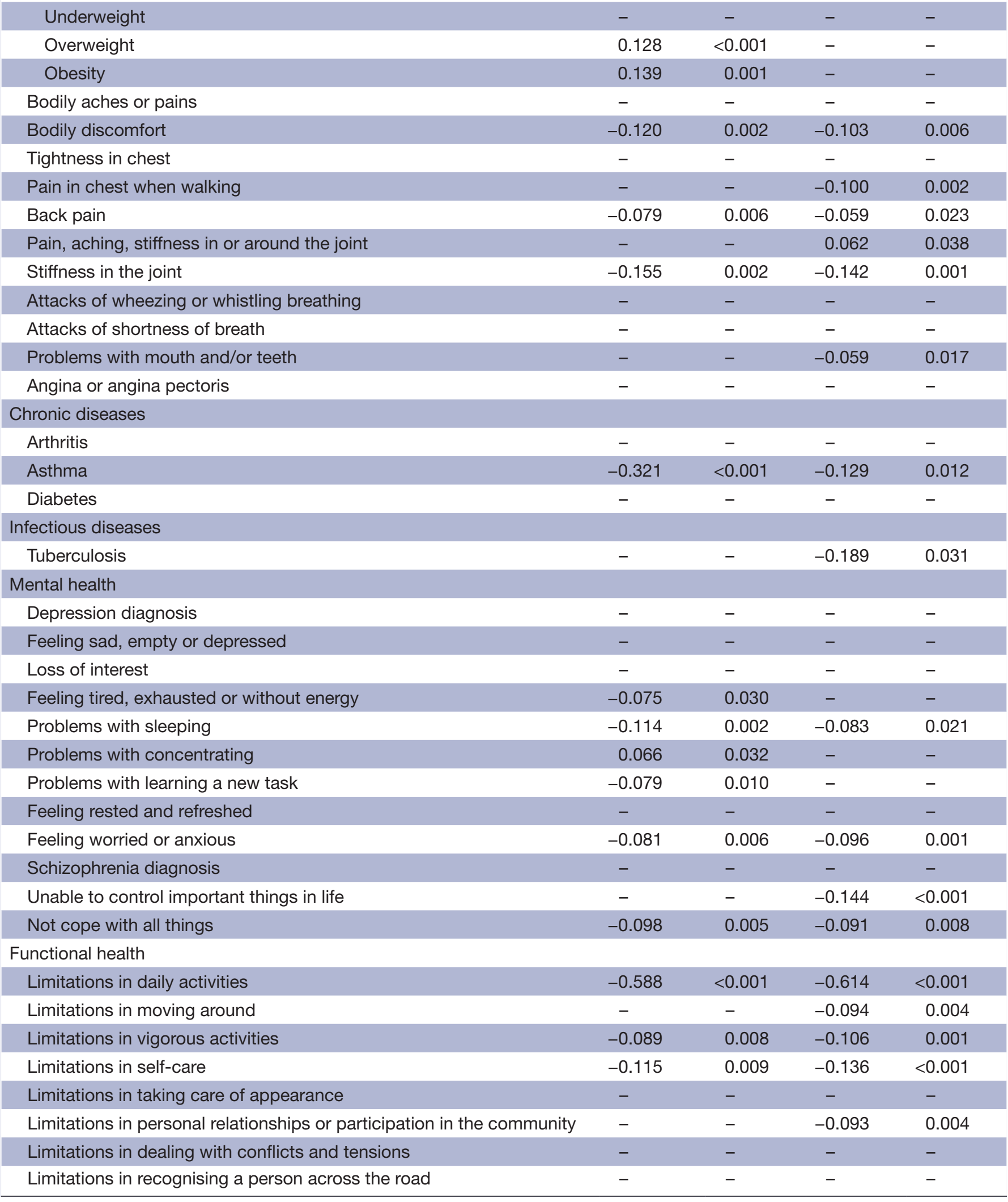




\begin{tabular}{|c|c|c|c|c|}
\hline & \multicolumn{2}{|c|}{ Men $n=4492$} & \multicolumn{2}{|c|}{ Women $\mathrm{n}=4736$} \\
\hline & B & P values & B & P values \\
\hline Limitations in reading & - & - & -0.086 & 0.023 \\
\hline \multicolumn{5}{|l|}{ Health behaviours } \\
\hline Smoking (yes) & -0.085 & $<0.001$ & -0.079 & 0.012 \\
\hline Drinking alcohol last 7 days & 0.096 & 0.010 & - & - \\
\hline Vigorous or moderate physical activity last 7 days & - & - & - & - \\
\hline Eating fruits daily & 0.070 & 0.013 & - & - \\
\hline Eating vegetables daily & - & - & - & - \\
\hline Adjusted $\mathrm{R}^{2}$ & 0.453 & & 0.483 & \\
\hline
\end{tabular}

*Very bad $=1$, very good $=5$.

†Adjusted for age, education, household income, employment, marital status, religion, residence and Indian states. BMI, Body Mass Index.

different testing coding schemes of SRH (eg, linear vs binary) ${ }^{86}$ The multidimensionality of SRH agrees with evidence that SRH functions as an umbrella indicator of respondents' general health, capturing a range of health dimensions ${ }^{49}$ - physical, mental and functional health ${ }^{50-62}$-and health behaviours. ${ }^{49} 586163$ To date, most of this evidence came from high-income countries; this study may be the first, to our knowledge, to support this finding in the general population of India.

Second, sensitivity analyses confirmed that SRH has similar construct validity across the age spectrum $(<36$, $36-59$ and $\geq 60$ years) and educational levels but with one exception: among respondents with post-secondary education, general health ratings were generally inconsistent with self-reported morbidity-a result that may have two explanations: first, this result may reflect unreliable estimations due to the low number of respondents with post-secondary education; and second, if true, this result could reflect an higher awareness effect due to a better access to healthcare, a phenomenon observed in high-income countries. ${ }^{87}$ Nevertheless, results from sensitivity analyses suggest that the SRH item may be used in general adult population surveys of India without restrictions on age.

This surprisingly good performance of the SRH item in India contradicts two validation studies conducted in low-income countries ${ }^{28} 40$ that reported low correlation of SRH ratings with health as individuals age. A study of Onadja et al, conducted in Burkina Faso, ${ }^{28}$ found that SRH among people $\geq 60$ years old essentially reflected functional limitations but not chronic conditions. Two reasons may explain this discrepancy with our study. First, cultural reporting styles as well as true health may differ between this country and India. Second, the study of Onadja tested a sum score of health indicators (number of chronic conditions, number of functional limitations) instead of health indicators themselves (as in our study). The second validation study, conducted by Cramm et $a l$ in India, ${ }^{40}$ found that older Indians ( $\geq 45$ years old) tended to perceive their general health more positively when compared with two biomarkers (grip strength, lung function). Because the study focused on respondents $\geq 45$ years old, Cramm et al could not conclude whether the optimistic health perception was widespread across younger age groups. Moreover, this study was based on the US version of the SRH item, which includes three positive ratings (excellent, very good and good), one medium rating (fair) and one negative rating (poor). Such ratings may explain in part the elevated proportion of positive perception of health. Our study used a more equilibrated distribution of ratings: two negative (very bad and bad), one medium (moderate) and two positive (good and very good). Finally, Cramm et al included different Indian states than in our study, so we cannot avoid that unmeasured cultural and linguistic characteristics may explain the discrepancies with our findings.

Third, our cross-cultural construct validation study comparing India with Switzerland with similar health indicators showed that the SRH item captured the same health dimensions in both countries, despite their important differences. The SRH item also performed better in India than Switzerland in terms of explained variance, mostly because the health ratings from Indian respondents were better distributed across the response options than those from Swiss respondents, which concentrated between the 'good' and 'very good' options. Such differences in the distribution of ratings may be explained by differences in levels of general population health and health expectations between the two countries.

Fourth, we found a satisfactory convergent validity of the SRH item, moderately correlated $(0.506)$ with the item 'satisfaction with health'. This result, while preliminary, consolidates the validity of the SRH item in India and calls for more comprehensive research on its convergent validity in India.

From these four arguments, we can conclude that the SRH item has satisfactory construct validity in the context of India and may be a reliable indicator of general health of the Indian population. This result contradicts the sceptical view of the SRH item used in low-income and 
middle-income countries. ${ }^{23}$ The health assessment of respondents living in these countries is supposed to be influenced by their social environment which may affect their judgement (eg, living in a socially disadvantaged area with high prevalence of diseases may lead respondents to consider some symptoms as normal). In our study, it is possible that some respondents may have underestimated the degree of severity of their illnesses and symptoms, despite being able to perceive and report them in the survey. Our study mostly focuses on the perception of illnesses and symptoms, not their severity, which could explain why we observed satisfactory construct validity of the SRH item. We agree that this study did not assess all aspects of the measurement reliability of this indicator (see the Limitations section) and thus should be considered with caution. However, this study represents support for the use of the SRH item as an indicator of general health of the Indian population. Practical implications of this study (subject to its limitations) may be that institutions conducting large-scale health surveys in India, such as the Ministry of Health and Family Welfare or the Ministry of Statistics and Programme Implementation, should include or continue to use the SRH item in their demographic and population health surveys.

\section{Limitations}

Nine limitations must be emphasised. First, the main limitation of this study is its cross-sectional design. Using a longitudinal design would allow for determining whether the SRH item is a spontaneous assessment or an enduring self-concept. ${ }^{88}$ Second, this study assessed the construct validity of the SRH item, but other types of validity need to be investigated, such as predictive, content and discriminant validity. Third, response options of the SRH item used in the WHS 2003 survey were very bad, bad, moderate, good and very good (ie, the WHO version). ${ }^{89}$ The comparison of the SRH item with data from other countries using the US version (poor, fair, good, very good, excellent) is then limited and requires re-scaling response options. ${ }^{89}$ Fourth, results are based on the data from a WHS' wave conducted in 2003 and are old in that respect (we aimed to find comparable SRH items for India and Switzerland, see robustness analyses). We believe that the datedness of the data is acceptable in a methodological study because the objective was to assess the construct validity of an indicator but not the prevalence of the general health of the Indian population. Fifth, we used multiple imputations for missing information on health predictor variables. Hence, misclassification bias is possible. Sixth, results of this study are limited to the general population of India and are not applicable to a clinical setting, even though the SRH item has been recommended to healthcare professionals as a routine indicator of patient general health status because of its good predictive value of patients' quality of life, ${ }^{8090}$ functional status and mortality. ${ }^{91}{ }^{92}$ Seventh, we did not examine construct validity of the SRH item among the oldest-old age group ( $\geq 80$ years old), a subgroup of the population who tend to underestimate their health decline. ${ }^{93}$ More research using Indian data is needed within this group. Eighth, the SRH item has various versions: various phrasings and response scales have been used. Even though versions of the SRH item are highly correlated and share similar construct and convergent validity, ${ }^{1-4}$ the conclusions of this study cannot be generalised to other versions of the SRH item. Ninth, the design of the WHS 2003 survey included 6 of the 29 Indian states and thus may not be representative of the whole general Indian population.

\section{CONCLUSION}

This study suggests that the single SRH item is a reliable indicator of general health in the population of India. However, considering the limitations of this study, more research is needed to have conclusive evidence of its reliability in the context of India, in particular test-retest longitudinal studies and studies including all states and union territories of India."

Contributors Conceived and designed the study: all coauthors. Analysed the data: SS, SC. Drafted the manuscript: CB-J, SC. Read and commented on the paper: all authors.

Funding This project, 'Health inequalities in India and Switzerland: Measurement and distribution of well-being and vulnerability', was funded by the Indo-Swiss Joint Research Programme in the Social Sciences and supported by the Swiss State Secretariat for Education and Innovation and the Indian Council for Social Science Research.

Competing interests None declared.

Patient consent Not required.

Provenance and peer review Not commissioned; externally peer reviewed. Data sharing statement № additional data are available.

Open access This is an open access article distributed in accordance with the Creative Commons Attribution Non Commercial (CC BY-NC 4.0) license, which permits others to distribute, remix, adapt, build upon this work non-commercially, and license their derivative works on different terms, provided the original work is properly cited, appropriate credit is given, any changes made indicated, and the use is non-commercial. See: http://creativecommons.org/licenses/by-nc/4.0

\section{REFERENCES}

1. DeSalvo KB, Fisher WP, Tran K, et al. Assessing measurement properties of two single-item general health measures. Qual Life Res 2006;15:191-201.

2. Robinson-whelen S, Kiecolt-glaser J. The importance of social versus temporal comparison appraisals among older adults. J Appl Soc Psychol 1997;27:959-66.

3. Eriksson I, Undén AL, Elofsson S. Self-rated health. Comparisons between three different measures. Results from a population study. Int J Epidemiol 2001;30:326-33.

4. Manderbacka $\mathrm{K}$, Lundberg $\mathrm{O}$. Examining points of reference of self-rated health among Swedish oldest old. Arch Gerontol Geriatr 1996;23:47-60

5. Lundberg $\mathrm{O}$, Manderbacka K. Assessing reliability of a measure of self-rated health. Scand J Soc Med 1996;24:218-24.

6. Martikainen P, Aromaa A, Heliövaara M, et al. Reliability of perceived health by sex and age. Soc Sci Med 1999;48:1117-22.

7. Cox B, van Oyen $\mathrm{H}$, Cambois $\mathrm{E}$, et al. The reliability of the minimum European health module. Int J Public Health 2009;54:55-60.

8. Boardman JD. Self-rated health among U.S. adolescents. J Adolesc Health 2006;38:401-8.

9. Cousins SO. Validity and reliability of self-reported health of persons aged 70 and older. Health Care Women Int 1997;18:165-74. 
10. DeSalvo KB, Bloser N, Reynolds K, et al. Mortality prediction with a single general self-rated health question. A meta-analysis. $J$ Gen Intern Med 2006;21:267-75.

11. Idler EL, Benyamini Y. Self-rated health and mortality: a review of twenty-seven community studies. J Health Soc Behav 1997;38:21-37.

12. Lima-Costa MF, Cesar CC, Chor D, et al. Self-rated health compared with objectively measured health status as a tool for mortality risk screening in older adults: 10-year follow-up of the Bambuí Cohort Study of Aging. Am J Epidemiol 2012;175:228-35.

13. Bopp M, Braun J, Gutzwiller F, et al. Health risk or resource? Gradual and independent association between self-rated health and mortality persists over 30 years. PLoS One 2012;7:e30795.

14. Halford C, Wallman T, Welin L, et al. Effects of self-rated health on sick leave, disability pension, hospital admissions and mortality. A population-based longitudinal study of nearly 15,000 observations among Swedish women and men. BMC Public Health 2012;12:1103.

15. Benyamini Y, Idler EL. Community studies reporting association between self-rated health and mortality: additional studies, 1995 to 1998. Res Aging 1999;21:392-401.

16. Heistaro S, Jousilahti P, Lahelma E, et al. Self rated health and mortality: a long term prospective study in eastern Finland. $J$ Epidemiol Community Health 2001;55:227-32.

17. Pu C, Bai YM, Chou YJ. The impact of self-rated health on medical care utilization for older people with depressive symptoms. Int $J$ Geriatr Psychiatry 2013;28:479-86.

18. Pu C, Tang GJ, Fang YT, et al. Which domain of self-rated health best predicts medical care utilization among Taiwanese adults? $\mathrm{J}$ Epidemiol 2012;22:417-24.

19. DeSalvo KB, Jones TM, Peabody J, et al. Health care expenditure prediction with a single item, self-rated health measure. Med Care 2009;47:440-.

20. Jürges $\mathrm{H}$. True health vs response styles: exploring cross-country differences in self-reported health. Health Econ 2007;16:163-78.

21. Jylhä M, Guralnik JM, Ferrucci L, et al. Is self-rated health comparable across cultures and genders? J Gerontol B Psychol Sci Soc Sci 1998;53:S144-S152.

22. Hardy MA, Acciai F, Reyes AM. How health conditions translate into self-ratings: a comparative study of older adults across Europe. $J$ Health Soc Behav 2014;55:320-41.

23. Sen A. Health: perception versus observation. BMJ 2002;324:860-1.

24. Salomon JA, Tandon A, Murray CJ. Comparability of self rated health: cross sectional multi-country survey using anchoring vignettes. BMJ 2004;328:258.

25. $\mathrm{Xu} \mathrm{H}, \mathrm{Xie} \mathrm{Y}$. Assessing the effectiveness of anchoring vignettes in bias reduction for socioeconomic disparities in self-rated health among Chinese adults. Sociol Methodol 2016;46:84-120.

26. Bago d'Uva T, Van Doorslaer E, Lindeboom M, et al. Does reporting heterogeneity bias the measurement of health disparities? Health Econ 2008;17:351-75.

27. Murray CJL, Özaltin E, Tandon A. Empirical evaluation of the anchoring vignette approach in health survey. In: Murray CJL, Evans DB, eds. Health systems performance assessment: debates, methods and empiricismGeneva: World Health Organization, 2003: 369-99.

28. Onadja Y, Bignami S, Rossier C, et al. The components of self-rated health among adults in Ouagadougou, Burkina Faso. Popul Health Metr 2013;11:15.

29. Ardington C, Gasealahwe B. Mortality in South Africasocioeconomic profile and association with self-reported health. Dev South Afr 2014;31:127-45.

30. Freidoony L, Chhabi R, Kim CS, et al. The components of selfperceived health in the Kailali district of Nepal: a cross-sectional survey. Int J Environ Res Public Health 2015;12:3215-31.

31. Macia E, Duboz P, Gueye L. Les déterminants de l'auto-évaluation de la santé à Dakar. Une étude anthropo-biologique exploratoire. BMSAP 2016;28-84-97.

32. Haque SMR, Tisha S, Rahman MO. Assessing self-reported general health in $r$ ural Bangladesh: updating a user friendly tool. Int J Prev Med 2017;6:19-27.

33. Wu S, Wang R, Zhao $\mathrm{Y}$, et al. The relationship between self-rated health and objective health status: a population-based study. BMC Public Health 2013;13:320.

34. Xu J, Zhang J, Feng L, et al. Self-rated health of population in Southern China: association with socio-demographic characteristics measured with multiple-item self-rated health measurement scale. BMC Public Health 2010;10:393.

35. Abdulrahim S, El Asmar K. Is self-rated health a valid measure to use in social inequities and health research? Evidence from the PAPFAM women's data in six Arab countries. Int J Equity Health 2012;11:53.
36. National Sample Survey Office India. Survey on health care July-June 1995-96, NSS 52nd round: Ministry of Statistics and Programme Implementation (MOSPI). Government of India, 1996.

37. National Sample Survey Office India Social Consumption. Health, NSS 71st round: Jan-June 2014: Ministry of Statistics and Programme Implementation (MOSPI). Government of India, 2015.

38. National Sample Survey Office India. Survey on morbidity and health care: NSS 60th round: January 2004-June 2005: Ministry of Statistics and Programme Implementation (MOSPI). Government of India, 2015.

39. Subramanian SV, Subramanyam MA, Selvaraj S, et al. Are self-reports of health and morbidities in developing countries misleading? Evidence from India. Soc Sci Med 2009;68:260-5.

40. Cramm JM, Bornscheuer L, Selivanova A, et al. The health of India's elderly population: a comparative assessment using subjective and objective health outcomes. J Popul Ageing 2015;8:245-59.

41. Hirve S, Juvekar S, Sambhudas S, et al. Does self-rated health predict death in adults aged 50 years and above in India? Evidence from a rural population under health and demographic surveillance. Int J Epidemiol 2012;41:1719-27.

42. Falk H, Skoog I, Johansson L, et al. Self-rated health and its association with mortality in older adults in China, India and Latin America-a 10/66 Dementia Research Group study. Age Ageing 2017;46:932-9.

43. Chen B, Mahal A. Measuring the health of the Indian elderly: evidence from national sample survey data. Popul Health Metr 2010;8:30.

44. India COProvisional Population Totals Paper 1 of 2011 India Series 1: Office of the Registrar General \& Census Commissioner, 2011. Available from: http://www.censusindia.gov.in/2011-prov-results/ prov results paper1 india.html

45. Nongkynrih B, Patro BK, Pandav CS. Current status of communicable and non-communicable diseases in India. $J$ Assoc Physicians India 2004;52:118-23.

46. Üstün TB, Chatterji S, Mechbal A. The World health surveys. In: Murray CJL, Evans DB, eds. Health systems performance assessment. debates, methods and empiricism. edn. Geneva: World Health Organization, 2003: 797-808.

47. Arokiasamy P, Guruswamy M, Roy TK. Health system performance assessment-world health survey, 2003-India. Mumbai, Geneva, New Delhi: International Institute for Population Sciences \& World Health Organisation \& World Health Organisation-India-WR Office, 2006.

48. World Health Organization. World health survey. Geneva, 2003.

49. Shooshtari S, Menec V, Tate R. Comparing predictors of positive and negative self-rated health between younger (25-54) and older (55+) Canadian adults. Res Aging 2007;29:512-54.

50. Johnson TP, Stallones L, Garrity TF, et al. Components of selfrated health among adults: analysis of multiple data sources. Int $Q$ Community Health Educ 1990;11:29-41.

51. Perruccio AV, Katz JN, Losina E. Health burden in chronic disease: multimorbidity is associated with self-rated health more than medical comorbidity alone. J Clin Epidemiol 2012;65:100-6.

52. Pinquart M. Correlates of subjective health in older adults: a metaanalysis. Psychol Aging 2001;16:414-26.

53. Hooker K, Siegler IC. Separating apples from oranges in health ratings: perceived health includes psychological well-being. Behavior, Health, \& Aging 1992;2:81-92.

54. Kaplan G, Baron-Epel O. What lies behind the subjective evaluation of health status? Soc Sci Med 2003;56:1669-76.

55. Krause NM, Jay GM. What do global self-rated health items measure? Med Care 1994;32:930-42.

56. Manderbacka K. Examining what self-rated health question is understood to mean by respondents. Scand J Soc Med 1998;26:145-53.

57. Simon JG, De Boer JB, Joung IM, et al. How is your health in general? A qualitative study on self-assessed health. Eur J Public Health 2005;15:200-8.

58. Yamada C, Moriyama K, Takahashi E. Self-rated health as a comprehensive indicator of lifestyle-related health status. Environ Health Prev Med 2012;17:457-62.

59. Singh-Manoux A, Martikainen P, Ferrie J, et al. What does self rated health measure? Results from the British Whitehall II and French Gazel cohort studies. J Epidemiol Community Health 2006;60:364-72.

60. Mora PA, DiBonaventura MD, Idler E, et al. Psychological factors influencing self-assessments of health: toward an understanding of the mechanisms underlying how people rate their own health. Ann Behav Med 2008;36:292-303.

61. Garbarski D, Dykema J, Croes KD, et al. How participants report their health status: cognitive interviews of self-rated health across 
race/ethnicity, gender, age, and educational attainment. BMC Public Health 2017;17:771.

62. Golini N, Egidi V. The latent dimensions of poor self-rated health: how chronic diseases, functional and emotional dimensions interact influencing self-rated health in italian elderly. Social Indicators Research 2016;128:321-39.

63. Manderbacka K, Lundberg O, Martikainen P. Do risk factors and health behaviours contribute to self-ratings of health? Soc Sci Med 1999;48:1713-20.

64. Sterne JA, White IR, Carlin JB, et al. Multiple imputation for missing data in epidemiological and clinical research: potential and pitfalls. BMJ 2009;338:b2393.

65. United Nations Educational SaCO, 2006. International standard classification of education 1997 Paris UNESCO. Available from: http://www.uis.unesco.org/Education/Pages/international-standardclassification-of-education.aspx

66. Selvamani Y, Arokiasamy P U. Effects of childhood and current socioeconomic status on health of older adults in India, China, Ghana, Mexico, Russia and South Africa: an analysis of WHOSAGE data. In: Hoque MN, Pecotte B, McGehee MA, eds. Applied demography and public health in the 21st century. edn. Cham: Springer International Publishing, 2017: 329-48.

67. Arokiasamy P, Uttamacharya, Jain K. Multi-morbidity, functional limitations, and self-rated health among older adults in India. SAGE Open 2015;5:215824401557164.

68. Goli S, Singh L, Jain K, et al. Socioeconomic determinants of health inequalities among the older population in India: a decomposition analysis. J Cross Cult Gerontol 2014;29:353-69.

69. Bora JK, Saikia N. Gender differentials in self-rated health and self-reported disability among adults in India. PLoS One 2015;10:e0141953.

70. Hirve S, Juvekar S, Lele P, et al. Social gradients in self-reported health and well-being among adults aged 50 and over in Pune District, India. Glob Health Action 2010;3:2128.

71. Hirve S, Oud JHL, Sambhudas S, et al. Unpacking self-rated health and quality of life in older adults and elderly in India: a structural equation modelling approach. Social Indicators Research 2014;117:105-19.

72. Brinda EM, Attermann J, Gerdtham UG, et al. Socio-economic inequalities in health and health service use among older adults in India: results from the WHO Study on Global AGEing and adult health survey. Public Health 2016;141:32-41.

73. Das BM, Roy SK. Socio-demographic correlates of self-rated health among Santals of rural West Bengal, India. Eurasian Journal of Anthropology 2014;5:1-13.

74. Rahman M, Khan HTA, Hafford-Letchfield T, et al. Socio-economic inequalities in health among older adults in two rural sub-districts in India and Bangladesh: a comparative cross-sectional study. Asian Population Studies 2017;13:292-305.
75. Selvamani Y, Singh P. Socioeconomic patterns of underweight and its association with self-rated health, cognition and quality of life among older adults in India. PLoS One 2018;13:e0193979.

76. Benyamini $Y$, Leventhal EA, Leventhal H. Gender differences in processing information for making self-assessments of health. Psychosom Med 2000;62:354-64.

77. Idler EL. Discussion: gender differences in self-rated health, in mortality, and in the relationship between the two. Gerontologist 2003;43:372-5.

78. Manderbacka K, Lahelma E, Martikainen P. Examining the continuity of self-rated health. Int J Epidemiol 1998;27:208-13.

79. Idler EL. Age differences in self-assessments of health: age changes, cohort differences, or survivorship? J Gerontol 1993;48:S289-S300.

80. Jylhä M. What is self-rated health and why does it predict mortality? Towards a unified conceptual model. Soc Sci Med 2009;69:307-16

81. Peersman W, Cambier D, De Maeseneer J, et al. Gender, educational and age differences in meanings that underlie global self-rated health. Int J Public Health 2012;57:513-23.

82. Layes A, Asada Y, Kepart G. Whiners and deniers-what does selfrated health measure? Soc Sci Med 2012;75:1-9.

83. Maddox GL, Douglass EB. Self-assessment of health: a longitudinal study of elderly subjects. J Health Soc Behav 1973;14:87-93.

84. Crossley TF, Kennedy S. The reliability of self-assessed health status. J Health Econ 2002;21:643-58.

85. Zajacova A, Dowd JB. Reliability of self-rated health in US adults. Am J Epidemiol 2011;174:977-83.

86. Manor O, Matthews S, Power C. Dichotomous or categorical response? Analysing self-rated health and lifetime social class. Int $J$ Epidemiol 2000;29:149-57.

87. Mirowsky J, Ross CE. Education, social status, and health. New York: Aldine de Gruyter, 2003.

88. Bailis DS, Segall A, Chipperfield JG. Two views of self-rated general health status. Soc Sci Med 2003;56:203-17.

89. Jürges H, Avendano M, Mackenbach JP. Are different measures of self-rated health comparable? An assessment in five European countries. Eur J Epidemiol 2008;23:773-81.

90. Crane HM, Van Rompaey SE, Dillingham PW, et al. A single-item measure of health-related quality-of-life for HIV-infected patients in routine clinical care. AIDS Patient Care STDS 2006;20:161-74.

91. Fleishman JA, Crystal S. Functional status transitions and survival in HIV disease: evidence from the AIDS costs and service utilization survey. Med Care 1998;36:533-43.

92. Shadbolt B, Barresi J, Craft P. Self-rated health as a predictor of survival among patients with advanced cancer. J Clin Oncol 2002;20:2514-9.

93. Henchoz K, Cavalli S, Girardin M. Health perception and health status in advanced old age: a paradox of association. Journal of Aging Studies 2008;22:282-90 